\title{
Genetic Influences on Social Relationships: Sex Differences in the Mediating Role of Personality and Social Cognition
}

\section{Eiluned Pearce, et al. [full author details at the end of the article]}

Received: 12 September 2019 / Revised: 21 October 2019 / Accepted: 24 October 2019 Published online: 26 November 2019

(C) The Author(s) 2019

\section{Abstract}

Objectives In humans (and primates more generally), evolutionary fitness arises by two separate routes: conventional reproduction build around dyadic relationships and, reflecting the processes of group augmentation selection, how well individuals are embedded in their community. These processes are facilitated by a suite of genetically inherited neuroendocrines and neurotransmitters. It is not, however, known whether these effects are directly due to genetic factors or are mediated by aspects of personality, or whether there are sex differences in the way this is organised.

Methods We examine whether dispositional factors related to the processing of social information, such as personality (Big 5 and Impulsivity), attachment style (Anxious and Avoidant dimensions) and sociocognitive capacity (emotion recognition) mediate associations between variation in receptor genes for oxytocin, vasopressin, beta-endorphin, dopamine, serotonin, testosterone and two core social relationship indices (the Sociosexual Orientation Index [SOI] and Support Network size).

Results In men, variation in dopamine genes indirectly influences SOI through its effect on Impulsivity. In contrast, in women, variation in endorphin and vasopressin genes independently affect Openness to Experience, which mediates indirect effects of these genes on SOI. Moreover, endorphin gene variation also impacts on Network Size in women (but not men), via Extraversion.

Conclusions These findings reveal that dispositional aspects of personality mediate some genetic effects on behaviour, thereby extending our understanding of how genetic and dispositional variation interact to determine individual differences in human sexual and social cognition and behaviour. The differences between the sexes seem to reflect differences in the two sexes' social strategies.

Keywords Mentalising $\cdot$ Inhibition $\cdot$ Sex differences $\cdot$ Sexual relationships $\cdot$ Social networks · Endorphin · Dopamine $\cdot$ Serotonin $\cdot$ Oxytocin $\cdot$ Testosterone $\cdot$ Vasopressin

Electronic supplementary material The online version of this article (https://doi.org/10.1007/s40750-01900120-5) contains supplementary material, which is available to authorized users. 


\section{Introduction}

The decisions we make in our highly dynamic social world have profound implications for individual fitness, both in terms of survival chances and opportunities to reproduce successfully. For humans, as for all primates, that social context involves not only the kinds of dyadic relationships that most evolutionary and psychological studies have focused on, but also the wider social network, or community, within which these dyadic relationships are embedded. The result is a trade off between the short term benefits to be gained at the level of individual interactions and the long term benefits to be gained through being embedded in a functional group (group augmentation selection: Kokko and Johnstone 2001; Dunbar 2012). Forming a new close romantic relationship, for example, usually results in the downgrading of two other close relationships (BurtonChellew and Dunbar 2015), and that has consequences for the benefits that these provided. Similarly, exposure to a new social environment commonly results in the replacement of up to $40 \%$ of one's social network, including many close friendships (Saramäki et al. 2014; Roberts and Dunbar 2015), and this involves trade offs between the costs and benefits of different relationships. It has been the capacity to manage these trade offs so as to gain the benefits of living in groups while not completely foregoing short term benefits at the individual level that, in many ways, has been the key to primate, and especially human, evolutionary success.

We have previously shown that the different domains of our social world are influenced by different neurochemicals (in particular, endorphins, oxytocin and dopamine) (Pearce et al. 2017, 2018a, b). Nonetheless, it is unlikely that this involves simple genes/behaviour relationships. It is likely that any genetic effects on behaviour are mediated through other aspects of cognition. Past work has indicated that individual variation in social behaviour is likely to be influenced by both genetic variation and dispositional profiles comprising facets such as personality, attachment style (internal cognitive-affective representation with regard to close relationship partners: Brennan et al. 1998), impulsivity (the capacity to inhibit prepotent responses) and sociocognitive skills such as the ability to identify others' emotional expressions. However, as yet, little has been done to investigate whether these putative genetic effects on social behaviour are mediated by these dispositional factors. In this paper, we explore whether an individual's personality, attachment style and sociocognitive skills mediate genetic influences on individual differences in two key aspects of sociability: (i) dyadic relationships in the form of romantic relationships (indexed as sociosexual orientation: Penke and Asendorpf 2008) and (ii) the wider support network the individual is embedded in (indexed as the number of individuals who we turn to for help and support in times of difficulty and distress: Dunbar and Spoors 1995; Sutcliffe et al. 2012).

That aspects of personality might mediate between the genetic underpinnings of behaviour and these behavioural outcomes is suggested by evidence for both the steps in this chain. We briefly summarise this evidence, beginning with the links between aspects of personality and our outcome behaviours. We consider not just conventional personality dimensions, but related aspects of social cognition like impulsivity, attachment style and sociocognitive skills like the ability to identify emotional signals.

Extraverts have been found to have more people in each intimacy layer of their social networks (Pollet et al. 2011), and a longitudinal study looking at the effect of 
personality on social relationships during the transition to university found that Extraversion related positively both to network size and whether someone became romantically involved (Asendorpf and Wilpers 1998). Moreover, Agreeableness was negatively related to having conflict with peers and Conscientiousness was positively related to the frequency of contact with family members (Asendorpf and Wilpers 1998), both of which might be expected to impact on network size and maintenance. Extraversion and Agreeableness have also been associated with various dimensions of sexuality (Schmitt and Buss 2000), and, in a cross-cultural study, short-term and promiscuous mating was related positively to Openness and Extraversion, negatively to Conscientiousness and Agreeableness, and not at all to Neuroticism in both sexes (Schmitt and Shackelford 2008). In addition, individuals with partners low in Agreeableness and Conscientiousness are less satisfied with their relationship and are more likely to consider affairs (Shackelford and Goetz 2008), suggesting that scores on these traits may affect both one's own and one's partner's behaviour. Other studies have suggested that the relationship between personality and sociosexual attitudes might be mediated by other physiological mechanisms such as cortisol (Wilson et al. 2015).

Impulsivity per se does not normally feature in the list of personality dimensions, but we are particularly interested in this trait because it indexes an individual's willingness to inhibit prepotent responses in the light of their potential consequences (e.g. the effect that a one night stand might have on an existing romantic relationship). The capacity to inhibit prepotent responses in this way has been proposed as a key requisite for maintaining complex primate societies: individuals delaying or foregoing their own gratification in order to compromise with others allows greater coordination between group members (Dunbar and Shultz 2017; Launay et al. 2015). Indeed, the capacity to inhibit prepotent responses increases with brain size across primate species (Shultz and Dunbar 2010; MacLean et al., 2014). The ability to inhibit inappropriate responses or delay gratification has been linked to better social skills in both children (Carlson et al. 2002, 2004; Casey et al. 2011; Rhoades et al. 2009; Mischel and Shoda 1976) and adults (Moffitt et al. 2001; Launay et al. 2015). Several studies have found that individuals who score high on trait Impulsivity find it more difficult to inhibit prepotent responses (Aichert et al. 2012; Kam et al. 2012; Logan et al. 1997). Individuals who are highly Impulsive may be more likely to engage impulsively in short-term sexual relationships and thus have high sociosexual orientation scores. In addition, we might expect that highly impulsive individuals would be less reliable as friends and less likely to spend the considerable time investment required to create and maintain close relationships (Miritello et al. 2013; Roberts and Dunbar 2011; Sutcliffe et al. 2012; Hall 2019). Highly impulsive people might therefore be expected to have smaller support social network layers comprising close intimates (as opposed to overall network size) than those who are more dependable and consistent in servicing their friendships.

In addition to personality, Attachment Style in close friendships is also likely to influence support network size (Pearce et al. 2017; Wei et al. 2007). Attachment style ranges across two dimensions of insecurity: Anxious Attachment measures the degree to which an individual fears rejection and abandonment and doubts their own desirability as a relationship partner, whereas Avoidant Attachment characterizes the extent to which an individual seeks to emotionally distance themselves from relationships and prefers to be self-reliant due to an underlying discomfort with interpersonal intimacy 
and interdependence (Brennan et al. 1998; Gillath et al. 2008). We expect that those with high scores on the Avoidant dimension are likely to have fewer close friendships, whereas individuals who score highly on the Anxious dimension, with concomitant fears of abandonment, might maintain larger support networks as an insurance policy. In terms of Sociosexual Orientation, a plausible prediction would be that those scoring high on the Avoidant dimension would lean towards shorter-term relationships, and individuals with an Anxious Attachment style might be more concerned with longerterm relationships.

As well as personality and Attachment Style influencing individuals' social behaviour, we might expect individuals who have superior sociocognitive skills to be better able to maintain larger social networks. One important skill is the ability to identify emotional expressions on people's faces, which is an aspect of cognitive empathy (the capacity to construct a working model of the affective states of others: Reniers et al. 2009). Someone who is more skilled at identifying others' emotive expressions might require less cognitive load, and so might be able to manage a larger number of social partners. In support of this, higher-level mentalising abilities are positively correlated with social network size, suggesting that sociocognitive abilities support the maintenance of more social ties (Launay et al. 2015; Powell et al. 2012; Stiller and Dunbar 2007). It may be that reading a potential partner's facial expressions also plays a role in successful mate attraction, but sociocognitive skills would not be expected to influence other aspects of Sociosexual Orientation such as attitudes to promiscuity and fantasising behaviour, and so may not be associated with Sociosexual Orientation overall.

Finally, we briefly consider the other half of the chain, namely the genetic underpinnings of behaviour. There is accumulating evidence to suggest that there are genetic influences on the conventional personality dimensions, attachment style, cognitive empathy, behaviour in sexual relationships, and engagement with wider social networks (Chen and Johnson 2012; Costa et al. 2009; Denes 2015; Lee Raby et al. 2013; Lo et al. 2017; Lucht et al. 2013; Pearce et al. 2017; Rodrigues et al. 2009; Schneiderman et al. 2014; Walum et al. 2008, 2012; Way et al. 2009; Wu et al. 2016). Moreover, personality also seems to be affected by genetic variation, having a relatively high heritability (Jang et al. 1996; Kim et al. 2013; Power and Pluess 2015; Vukasović and Bratko 2015; Yamagata et al. 2006). A number of studies have identified potential candidate genes underlying individual variation in personality (Carver et al. 2015; de Moor et al. 2012; Eisenberg et al. 2007; Hamidovic et al. 2009; Kim et al. 2013; Lo et al. 2017; Lukaszewski and Roney 2011; Varga et al. 2012). Overall, there is strong evidence of a genetic basis for personality variation, as well as other aspects of disposition (attachment style and sociocognitive capacities), sociosexual behaviour and sociality beyond dyadic interactions (see Pearce et al. 2017).

Thus, there is a prima facie case for testing the hypothesis that many of the sociocognitive aspects of our psychology mediate the previously observed relationships between the brain's social neuropeptides and neuroendocrines and sexual and social behaviour. Indeed, the feasibility of this is supported by Creswell et al.'s (2015) finding that social temperament (negative affectivity/Neuroticism, and social inhibition) mediates the relationship between oxytocin gene variation and social network diversity and social support.

Our previous work suggests genetic correlates of attitudes and behaviour in relation to both sexual relationships and the size of an individual's support network (Pearce 
et al. 2017; Pearce et al. 2018b). Here, we test whether these relationships are mediated by personality traits, Attachment Style, or sociocognitive skills. Having already reported on genetic associations with attachment style and cognitive empathy (Pearce et al. 2017), we firstly present new analyses testing for associations between personality traits (the Big Five and Impulsivity) and variation in receptor genes linked to the six neurochemicals known to play a role in social behaviour (oxytocin, vasopressin, testosterone, $\beta$-endorphin, dopamine and serotonin). We then use backwardsstepwise regression to find best-fit models predicting Sociosexual Orientation, as a measure of attitudes and behaviour in relation to sexual relationships, and Support Network Size, as a measure of social engagement beyond the dyad, from personality, attachment style, and sociocognitive skills. Finally, we explore possible mediation effects between genes found to influence each of the dispositional effects in the 'best-fit' models, and Sociosexual Orientation or Support Network Size. Because the two sexes differ in their reproductive strategies and behaviour (Vigil 2007; Mehta and Strough 2009; Benenson et al. 2009, 2011; Del Giudice 2011; Cross et al. 2013; Machin and Dunbar 2013; Coates 2015; Dyble et al. 2015; David-Barrett et al. 2015; Dunbar and Machin 2014; Bhattacharya et al. 2016; Dunbar 2016, 2018; Ghosh et al. 2019; Pearce et al. 2019; Archer 2019), and this may affect the way in which cognitive differences interact with these mechanisms (Feldman Barrett et al. 2000; Hall and Matsumoto 2004; Gardner and Gabriel 2004; Bell et al. 2006; Proverbio et al. 2008; Kiesow et al. 2019), we run all analyses separately for the two sexes.

\section{Material and Methods}

\section{Participants}

Healthy adults were recruited at three science festivals and a museum in the UK. Here we focus on the 757 participants (423 female) who identified as Caucasian and did not have a history of mental illness, as previously reported (Pearce et al. 2017; Pearce et al. 2018a). All participants had $\geq 90 \%$ genetic coverage (i.e. each participant was missing data for $<10 \%$ of the SNPs), but not all participants provided full responses to the survey questions, so sample size varies between analyses: see Table 1 for survey descriptive statistics and Table S1 for genotypic frequencies for each SNP.

The original data are available in full in the Online Supplementary Material.

\section{Procedure}

Participants completed a survey about their attitudes and behaviour with regard to social relationships, and provided a saliva sample for DNA extraction using OrageneDNA collection kits.

As our outcome variables, we measured general attitudes and behaviours in relation to sexual relationships using the revised Sociosexual Orientation Inventory (SOI) (Penke and Asendorpf 2008) and Support Social Network Size (following Roberts and Dunbar (2015), Stiller and Dunbar (2007), Dunbar and Spoors (1995) and Hill and Dunbar (2003), defined as the number of people participants would turn to for help and support during times of difficulty and distress). 
Table 1 Descriptive statistics (mean, standard deviation, minimum and maximum) for female and male participants

\begin{tabular}{|c|c|c|c|c|c|c|c|c|}
\hline \multirow[t]{2}{*}{ Variable } & \multicolumn{4}{|c|}{ Females } & \multicolumn{4}{|c|}{ Males } \\
\hline & $\mathrm{N}$ & Mean (SD) & Min. & Max. & $\mathrm{N}$ & Mean (SD) & Min. & Max. \\
\hline Age & 417 & $38.44(15.92)$ & 18.00 & 74.00 & 325 & $43.36(17.226)$ & 18.00 & 75.00 \\
\hline RMET & 422 & $27.76(3.66)$ & $16.00 *$ & 35.00 & 328 & $26.99(3.87)$ & $15.00 *$ & 36.00 \\
\hline Extraversion & 422 & $4.53(1.67)$ & 1.00 & 7.00 & 334 & $4.05(1.65)$ & 1.00 & 7.00 \\
\hline Agreeableness & 422 & $5.08(1.21)$ & 1.00 & 7.00 & 334 & 4.65 (1.19) & 1.50 & 7.00 \\
\hline Conscientiousness & 422 & $5.34(1.27)$ & 1.00 & 7.00 & 334 & $5.36(1.25)$ & 1.50 & 7.00 \\
\hline Neuroticism & 422 & $3.38(1.40)$ & 1.00 & 6.50 & 334 & $3.06(1.40)$ & 1.00 & 7.00 \\
\hline Openness & 422 & $5.27(1.24)$ & 1.00 & 7.00 & 333 & $5.29(1.21)$ & 1.50 & 7.00 \\
\hline Anxious attachment & 421 & $3.09(1.17)$ & 1.00 & 6.33 & 334 & $3.07(1.08)$ & 1.00 & 6.33 \\
\hline Avoidant attachment & 421 & $2.78(1.14)$ & 1.00 & 6.33 & 334 & $3.44(1.170$ & 1.00 & 6.67 \\
\hline Impulsivity & 423 & $1.98(0.43)$ & 1.00 & 3.40 & 334 & $1.98(0.40)$ & 1.00 & 3.27 \\
\hline Inner network size & 401 & $8.18(4.00)$ & 1.00 & 19.00 & 326 & $6.85(3.80)$ & 0.00 & 19.00 \\
\hline Sociosexual Orientation & 422 & $3.41(1.51)$ & 1.00 & 8.33 & 334 & 4.34 (1.57) & 1.13 & 9.00 \\
\hline
\end{tabular}

*Outliers below 15 were excluded

For mediation analysis, we used four separate measures: (1) the Standard Ten Item Personality Inventory (TIPI) scale (Gosling et al. 2003), which measures Openness, Conscientiousness, Extraversion, Agreeableness and Neuroticism/Emotional Stability (the 'Big 5': McCrae and Costa 1992) on a 7-point scale; (2) the short-form Barratt Impulsiveness Scale as a self-report measure of Impulsivity (Spinella 2007); (3) the Reading the Mind in the Eyes task (RMET, a measure of cognitive empathy: BaronCohen et al. 2001); and (4) the short form Experiences of Close Relationships scale as a measure of Anxious and Avoidant Attachment Styles (Wei et al. 2007), which we modified to relate to 'close friendships' rather than romantic relationships.

The independent variables are the SNP loci identified by Pearce et al. (2017) as being significantly correlated with our two outcome variables. Although we originally genotyped 33 SNPs from 9 genes coding for 6 neurochemicals, pruning based on linkage disequilibrium of 7 of these SNPs, and exclusion of a further 2 SNPs due to low minor allele frequencies, left 24 target SNPs in the final analyses (Pearce et al. 2017). These comprised 10 oxytocin receptor gene (OXTR) SNPs, 2 vasopressin receptor gene (AVPRla) SNPs, $5 \beta$-endorphin mu-opioid receptor gene (OPRM1) SNPs, 2 serotonin receptor gene (one each for HTR1A and HTR2A) SNPs, 2 dopamine receptor gene SNPs (one each for DRD1 and DRD2), 1 SNP for ANNK1 (which is downstream of $D R D 2$ and is closely functionally associated with it), and finally 1 SNP for the androgen receptor gene $(A R)$, to which testosterone binds. All these 24 SNPs had at least $95 \%$ coverage (for each of the SNPs $<5 \%$ of participants were missing data). As reported in Pearce et al. (2017), only rs237897, rs228485, rs265981, and rs648893 showed significant deviations from Hardy-Weinberg distributions (see Table S1 for genotypic frequencies). 


\section{Analysis}

We tested for associations between the 24 SNPs and both (i) the Big 5 dimensions and (ii) Impulsivity scores using PLINK version 1.9 (Chang et al. 2014; Purcell et al. 2007). Since rs6152 is located on the X chromosome and is therefore haploid in males, only additive models were run for this SNP. For the remaining 23 SNPs, we ran genotypic models that test for (1) additive effects, $a d d$, (2) deviation from additivity, domdev, and (3) genotypic effects (the combined effect of additivity and deviation from additivity, geno-2df). All models controlled for age and sex. Since the focus of this paper is on potential mediating effects, we summarise the genetic association results in the main text and Fig. 1. For the full statistical analysis, we direct the reader to the Supplementary Material and Table S2.

To explore whether individual differences in disposition can predict how individuals relate to sexual relationships and their wider social networks, we ran backwards stepwise regressions in SPSS to identify best-fit models for males and females separately. We initially entered all five Big 5 personality dimensions, Impulsivity, Anxious Attachment scores, Avoidant Attachment scores, RMET scores, and age. Sex differences in all independent variables are examined in the Supplementary Material, and correlations between all variables are given separately for males and females in Table S3.

To build on the backward regression results, we then used the dispositional (independent) variables identified in the best-fit models to conduct mediation analyses using the PROCESS plug-in for SPSS (Hayes 2013). To do so, we took the independent variables from the best-fit models from the backward regressions, and identified any SNPs that were significantly associated with them in this dataset (for personality those found here, or in Pearce et al. (2017) for Attachment Style and RMET scores). We then ran separate mediation models for each of those SNPs predicting SOI or Network Size, with each independent variable from the corresponding backward regression models becoming the mediating variable in the corresponding mediation analysis. For example, if Extraversion was found in the best-fit model predicting SOI scores, we added this as the mediator in a mediation model, with the associated SNP as the independent variable and SOI scores as the dependent variable.

All mediation models included age as a covariate. Outlying RMET scores $<15$ ( $>3$ SD below the mean) were excluded. Network Size of 20 were also excluded, since 20 spaces were provided for names in the survey and this created a ceiling effect: the frequency of participants naming 20 close network members was thus artificially elevated. Where appropriate, we tested both additive and domdev mediation models, and if visual inspection of graphs suggested a dominance effect we also ran a comparison between one homozygote and the carriers of the other allele e.g. GG versus Acarrier (AA/AG). As with the backwards regression models, we ran mediation analyses for males and females separately.

Despite the very large number of subjects included in this study, the number of dependent variables and SNPs in the genetics analysis inevitably raises issues of multiple testing. How to respond to these issues has been a matter of on-going debate for some considerable time. Bonferroni correction has often been the solution of choice, but it is widely considered to be overly conservative, not least because it disproportionately increases the risk of type 2 errors (accepting the null hypothesis 


\begin{tabular}{|c|c|c|c|c|c|c|c|c|c|}
\hline & \multicolumn{3}{|c|}{ From Pearce et al. (2017) } & \multirow{2}{*}{\multicolumn{6}{|c|}{$\begin{array}{c}\text { New analyses reported here } \\
\text { Personality } \\
\end{array}$}} \\
\hline & \multirow{2}{*}{ 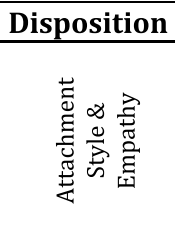 } & \multirow{2}{*}{ 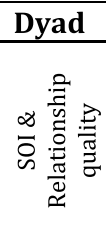 } & \multirow{2}{*}{ 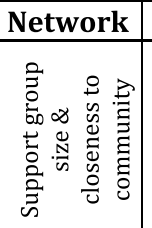 } & & & & & & \\
\hline & & & & $\mathbf{0}$ & C & $\mathbf{E}$ & $\mathbf{A}$ & $\mathbf{N}$ & 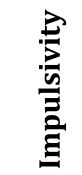 \\
\hline 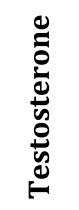 & $25 \%$ & $0 \%$ & $0 \%$ & $100 \%$ & $0 \%$ & $0 \%$ & $0 \%$ & $0 \%$ & $100 \%$ \\
\hline 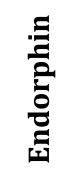 & $30 \%$ & $20 \%$ & $10 \%$ & $20 \%$ & $20 \%$ & $40 \%$ & $0 \%$ & $40 \%$ & $40 \%$ \\
\hline 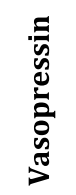 & $13 \%$ & $0 \%$ & $0 \%$ & $50 \%$ & $50 \%$ & $0 \%$ & $50 \%$ & $0 \%$ & $0 \%$ \\
\hline 苞 & $5 \% *$ & $45 \%$ & $10 \%$ & $10 \%$ & $20 \%$ & $0 \%$ & $10 \%$ & $30 \%$ & $0 \%$ \\
\hline 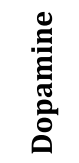 & $6 \% * *$ & $13 \% * *$ & $38 \% * *$ & $25 \%$ & $0 \%$ & $0 \%$ & $0 \%$ & $25 \%$ & $25 \%$ \\
\hline 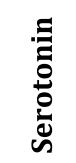 & $0 \%$ & $0 \%$ & $25 \%$ & $0 \%$ & $0 \%$ & $0 \%$ & $0 \%$ & $50 \%$ & $0 \%$ \\
\hline
\end{tabular}

\section{\begin{tabular}{|l|l|l|l}
$<20 \%$ & $20-30 \%$ & $31-50 \%$ & $>50 \%$ \\
\hline
\end{tabular}}

Fig. 1 Heatmap showing the percentage of SNPs from different neurochemical systems (testosterone 1 SNP, $\beta$-endorphin 5 SNPs, vasopressin 2 SNPs, oxytocin 10 SNPs, dopamine 4 SNPs, serotonin 2 SNPs) that are significantly associated with the different social domains (Pearce et al. 2017): "Disposition" here follows Pearce et al.'s (2017) terminology, relating to both attachment style and empathy measured using both RMET and the Empathy Quotient, "Dyad" refers to SOI scores and relationship quality measured by Relationship Assessment Scale, and "Network" refers both to support network size and closeness to the community measured using the Inclusion of Other in Self scale) and different dimensions of the Big 5 (self-ratings of the degree to Openness, Conscientiousness, Extravertion, Agreeableness, and Neuroticism) and with selfreported Impulsivity from the current analysis. Values for dopamine were given incorrectly in Pearce et al. (2017), and are here corrected 
when it should be rejected) in a way that only impossibly large samples could overcome (Nakagawa 2004; Garamszegi 2006; Narum 2006). Even professional statisticians disagree radically about its value (Rothman 1990; Schulz and Grimes 2005; Streiner and Norman 2011). Moreover, in analysing genetics data, Bonferroni correction does not take into account dependence between SNPs that are physically or functionally associated (Rice et al. 2008). One recommended solution, with a sounder statistical basis, is simply to discount the $N$ least significant results (where $N$ is the number of replicates) (Streiner and Norman 2011; see also Aldrich-Blake et al. 1971). Following professional advice, we used the mperm permutation function in PLINK to control for multiple testing, recognising that, in largescale genetics studies, few results will survive this correction; however, we can at least use this informally to gauge the magnitude of the relationships identified. In exploratory studies such as the present one, this is a statistically more justifiable approach because of the type 2 error problem. This issue does not affect the multiple regression or path analyses, which incorporate their own multiple testing controls.

\section{Results}

\section{Genetic Associations}

To provide the background for the mediation analyses, the broad pattern of significant associations across neurochemical/social domain categories and the different dimensions of personality is summarized as a heatmap in Fig. 1. Those for the three levels of social domain (first three columns on left) are from Pearce et al. (2017); those for the five OCEAN personality dimensions and impulsivity (last six columns on the right) are new analyses carried out for the present paper. The statistical analysis for each SNP and personality dimension is reported in full in the Electronic Supplementary Material (ESM) and Table S2.

\section{Backwards-Stepwise Regressions}

For females, backwards-stepwise regressions indicated that the best model (adjusted $R^{2}=0.218$ ) predicting SOI scores included age, Extroversion, Openness, and Impulsivity (Table 2). A similar model was obtained for males (adjusted $R^{2}=0.196$ ), except that it also included Agreeableness (Table 2).

For males, Support Network size was best predicted (adjusted $R^{2}=0.120$ ) by a model including age, Neuroticism and Avoidant Attachment style (Table 2). In contrast, Network size for females was best predicted (adjusted $R^{2}=0.110$ ) by age, RMET, Extraversion, Agreeableness, Anxious Attachment, and Avoidant Attachment scores, although RMET and Extraversion scores did not show significant partial effects (Table 2). Thus, both age and Avoidant Attachment were negatively related to network size in both sexes, but otherwise the best models differed between the sexes. Nonetheless, the two models explained a similar proportion of the variance in network size overall: $12 \%$ for males and $11 \%$ for females. 
Table 2 Best-fit models produced by backward regression models predicting SOI scores and Support Network size in males and females, giving the $t$ statistics for all independent variables with degrees of freedom in parentheses

\begin{tabular}{|c|c|c|c|c|c|c|}
\hline & \multicolumn{3}{|l|}{ Predicting SOI } & \multicolumn{3}{|c|}{ Predicting Support Network Size } \\
\hline & Best-fit model & $t(d f)$ & $\mathrm{p}$ & Best-fit model & $t(d f)$ & $\mathrm{p}$ \\
\hline \multirow[t]{5}{*}{ Males } & Age & $-2.291(318)$ & 0.023 & Age & $-2.337(310)$ & 0.02 \\
\hline & Extraversion & $3.848(318)$ & $<0.0001$ & Neuroticism & $-2.209(310)$ & 0.028 \\
\hline & Openness & $2.926(318)$ & 0.004 & Avoidant Attachment & $-5.054(310)$ & $<0.0001$ \\
\hline & Impulsivity & $4.097(318)$ & $<0.0001$ & & & \\
\hline & Agreeableness & $-2.671(318)$ & 0.008 & & & \\
\hline \multirow[t]{6}{*}{ Females } & Age & $-5.777(411)$ & $<0.0001$ & Age & $-1.799(391)$ & 0.073 \\
\hline & Extraversion & $3.910(411)$ & $<0.0001$ & Extraversion & 1.722 & 0.086 \\
\hline & Openness & $3.774(411)$ & $<0.0001$ & RMET & 1.957 & 0.051 \\
\hline & Impulsivity & $3.324(411)$ & 0.001 & Agreeableness & 2.671 & 0.008 \\
\hline & & & & Anxious Attachment & 2.483 & 0.013 \\
\hline & & & & Avoidant Attachment & -3.325 & 0.001 \\
\hline
\end{tabular}

\section{Mediation Analyses for SOI}

We report only models where significant indirect mediation effects were found. However, a number of additional models showing trend effects are given in the Electronic Supplementary Material, along with non-significant results.

For males only, Impulsivity was found to have a significant mediating effect between variation in the dopamine DRD1 SNP rs265981 and SOI when minor allele homozygotes (AA) were compared to carriers of the major allele (AG/GG): see Fig. 2. This indirect effect survived the inclusion of additional control variables: see ESM. Carriers of the $G$ allele were found to have significantly lower Impulsivity scores than those with AA genotypes (see Fig. 2). Impulsivity then had a significant positive relationship with SOI (Fig. 2). No direct (i.e. partial) or total effects were found between $D R D 1$ and SOI.

In contrast, for females, significant indirect additive effects on SOI were found via Openness for the endorphin OPRM1 rs3778151 gene, the vasopressin AVPR1a rs7294536 gene and the dopamine DRD2 rs4648317 (Fig. 3). No direct effects were found between any of these SNPs and SOI. The indirect effects for OPRM1 rs3778151 and AVPR1a rs7294536 survived the inclusion of additional control variables (see ESM).

\section{Mediation Analyses for Support Network Size}

There were no significant models for males. In females, a significant indirect domdev effect was found between endorphin OPRM1 rs495491 and Network Size, mediated by Extraversion (Fig. 4): heterozygotes were significantly less extraverted than homozygotes, and less extraverted individuals had smaller Support Networks. Further analysis suggested that this effect might be driven by the T-allele, since $\mathrm{T}$ carriers were 


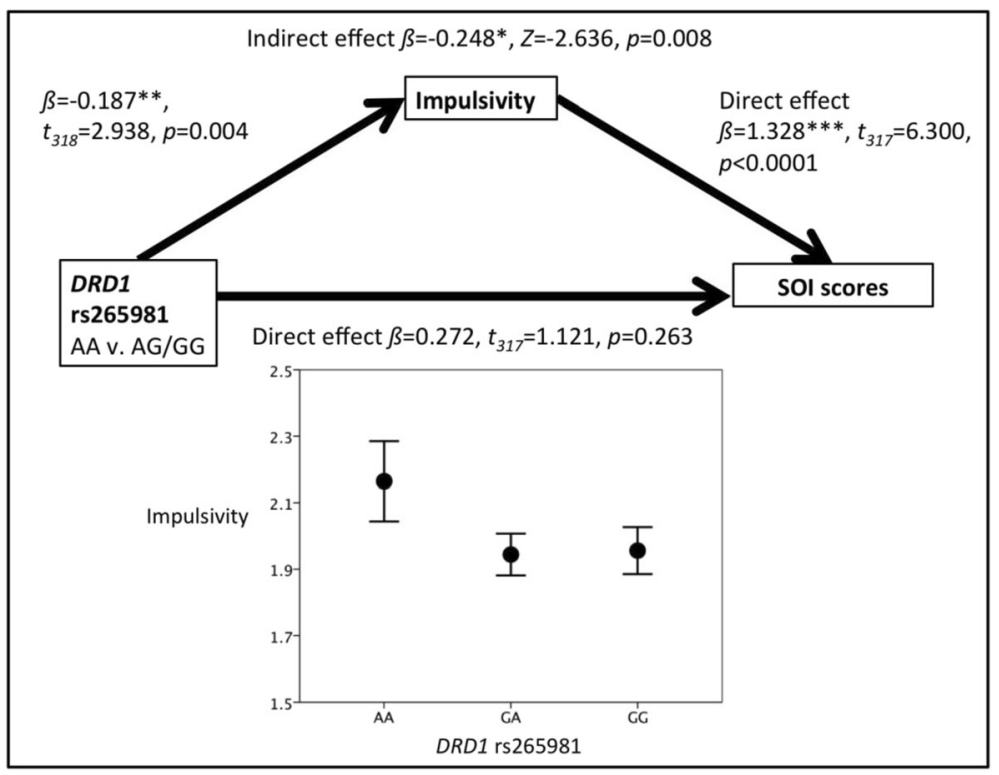

Fig. 2 Mediation analysis models between $D R D 1 \mathrm{rs} 265981$ and SOI scores, mediated via Impulsivity scores for male participants, and mean Impulsivity scores for males for different $D R D 1$ rs265981 genotypes. Means are shown \pm 2 S.E. $* p<0.05, * * p<0.005$, *** $p<0.0001$

significantly less extraverted than CC homozygotes $\left(t_{391}=-2.691, p=0.007\right)$ and this contrast also creates a significant indirect effect on Network Size $(Z=-1.984, p=$ 0.047). Although rs495491 continued to have a significant indirect effect on Network Size independently of OPRM1 rs3778151 (which itself showed a trend effect: ESM), including additional psychological traits as covariates meant that Extraversion was no longer significantly positively linked to Network Size: the partial effect of Extraversion was masked by the opposing negative effect of Avoidant Attachment (see ESM).

\section{Discussion}

As expected, we found significant genetic associations for all of the Big 5 personality dimensions and Impulsivity (see ESM for results and discussion). Moreover, we demonstrate that Sociosexual Orientation in both men and women is best predicted by Extraversion, Openness and Impulsivity: on average, individuals scoring highly on these traits were more likely to engage in, and condone, more promiscuous behaviour and casual sexual encounters. In addition, men who rated themselves as less Agreeable were also more likely to orientate towards relationships with minimal commitment, whereas Agreeableness did not appear to influence female SOI scores as strongly. These results broadly agree with the cross-cultural work of Schmitt and Shackelford (2008), except that Conscientiousness was not included in the best-fit models for either sex, perhaps due to overlap in the variance explained with the 'premeditation' facet of Impulsivity. The inclusion of Impulsivity in the best-fit model supports the suggestion that successful inhibition of prepotent responses is essential for the maintenance of dyadic social relationships, at least in the sexual domain. 

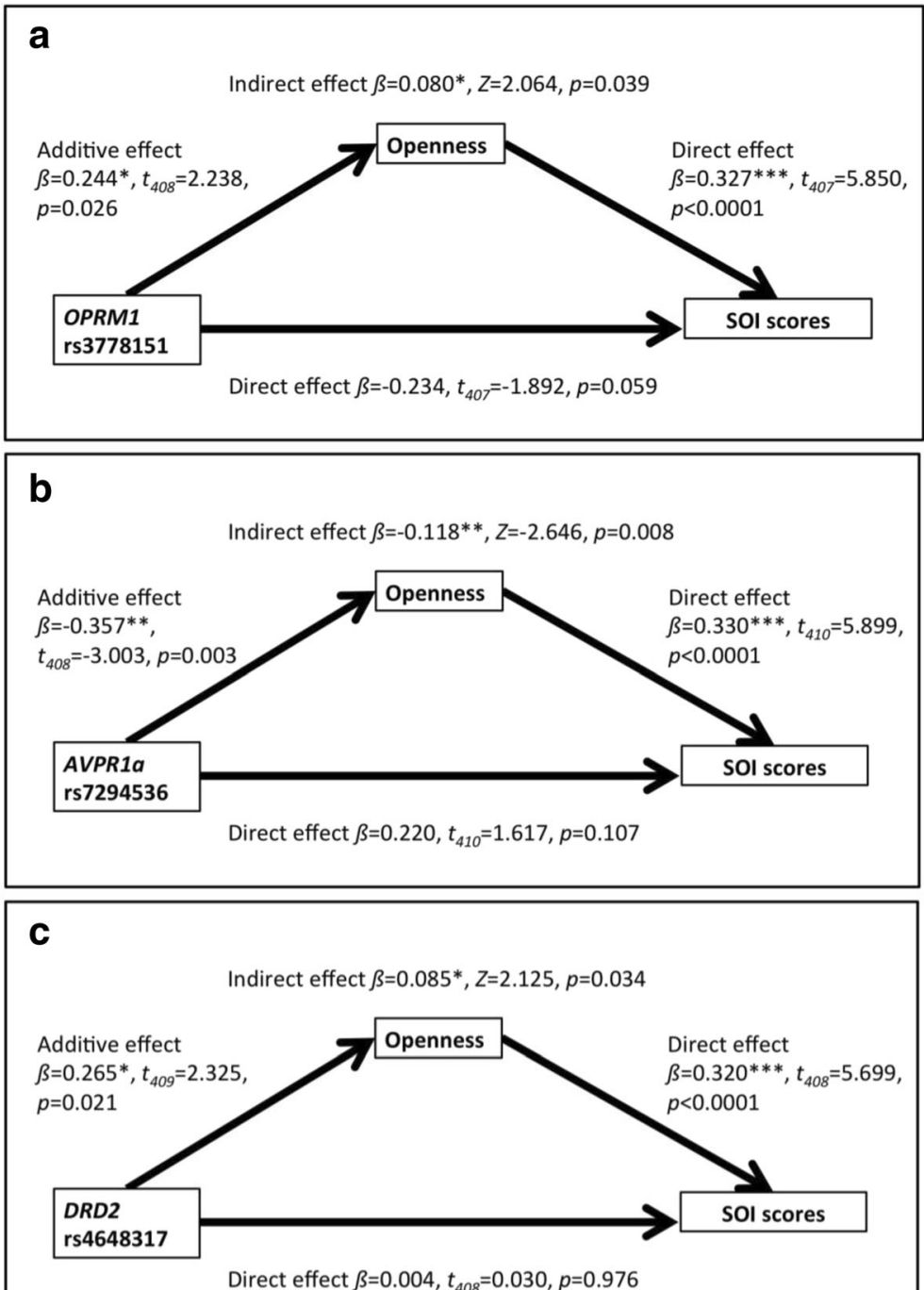

Fig. 3 Mediation analysis models between (A) OPRM1 rs3778151, (B) AVPR1a rs7294536 and (C) DRD2 rs4648317, and SOI scores, mediated via Openness scores for female participants. $* \mathrm{p}<0.05$, ** $\mathrm{p}<0.005$, $* * * \mathrm{p}<0.0001$

Furthermore, we found evidence that variation in specific genes indirectly influences how individuals relate to sexual relationships through their impact on personality traits in a sex-specific way. Whereas male Sociosexual Orientation was indirectly affected by variation in the dopamine $D R D 1$ gene through its impact on Impulsivity, this gene was found to affect Sociosexual Orientation only directly in females (see ESM). This supplements the previous finding that interaction between the dopamine $D R D 1$ and $D R D 2$ genes influences the age at which individuals become sexually active (Miller et al. 1999), corroborating a previous finding that dopamine receptor genes play a role in individual differences in sexual behaviour as well as impulsivity per se (Varga et al. 


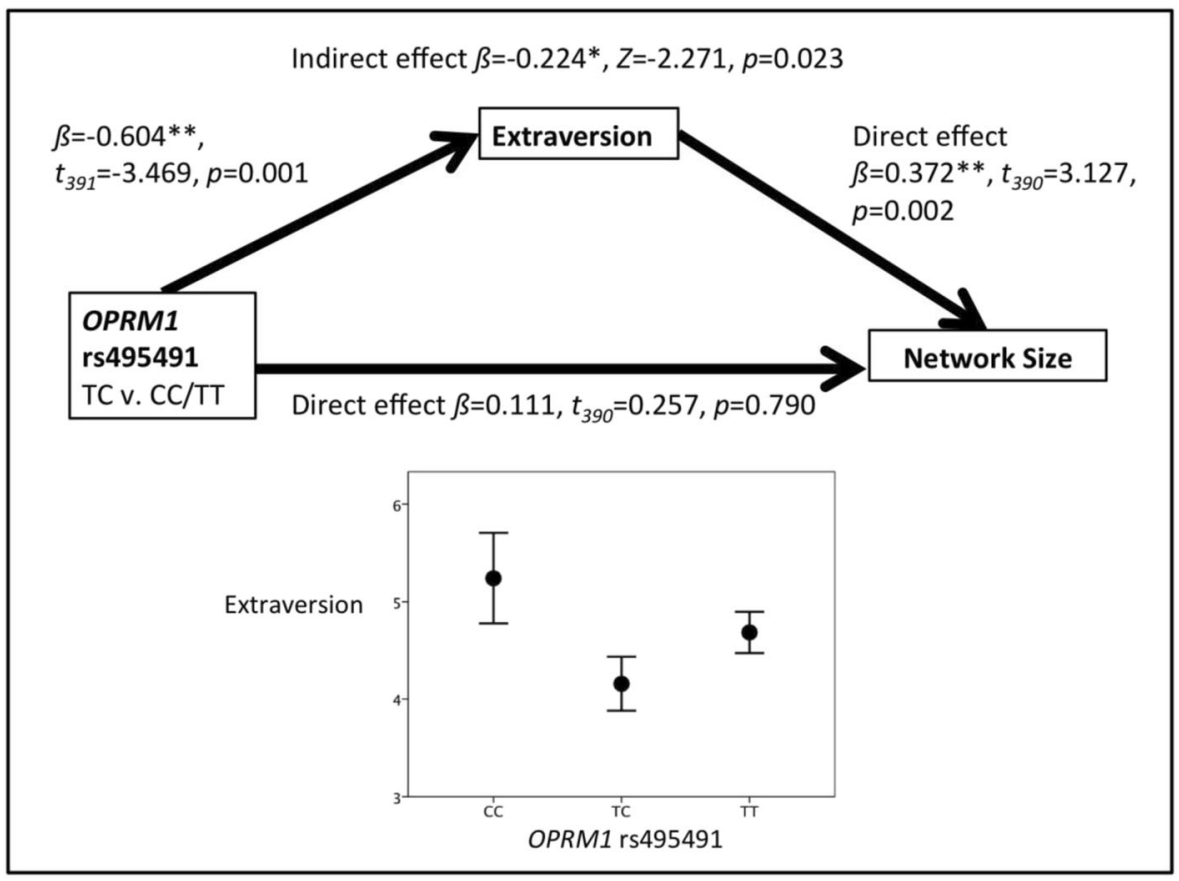

Fig. 4 Mediation analysis models between OPRM1 rs495491 and Network Size, mediated via Extraversion scores for female participants, and mean Extraversion scores for females for different OPRM1 rs495491 genotypes. Means are shown \pm 2 S.E. $* \mathrm{p}<0.05$, ** $\mathrm{p}<0.005, * * * \mathrm{p}<0.0001$

2012). Our findings add to these two lines of evidence by directly demonstrating that the effects of dopamine receptor gene variation on sexual cognition and behaviour are mediated by impulsivity in men. At the same time, the fact that this relates only to men indicates that a different causal pathway exists for women.

Indeed, female Sociosexual Orientation was indirectly affected by endorphin OPRM1, vasopressin $A V P R 1 a$ and dopamine $D R D 2$ genes through their independent additive effects on Openness. Although the effect of $D R D 2$ disappeared once the effect of the other genes were partialled out (see $E S M$ ), the mediated effect for DRD2 again indicates a role for the dopaminergic system in cognition and behaviour relating to sexual relationships, but this time through its impact on a different dimension of personality. Given the role of $\beta$ endorphin in experiencing social reward (Troisi et al. 2010) and social bonding (Dunbar 2010; Machin and Dunbar 2011; Loseth et al. 2014), it is perhaps unsurprising that it affects SOI. As well as these mediated effects, variation in OPRM1 (rs2075572 and rs648893) and DRD1 (rs265981) were found to yield direct effects on relationship quality and Sociosexual Orientation, respectively (Pearce et al. 2017), again highlighting that individual differences in these reward systems impact on sexual cognition and behaviour.

Previous work has linked behaviour relating to pair-bonding, such as relationship status and quality, to AVPRla variation in men (Walum et al. 2008) but OXTR variation in women (Walum et al. 2012). In contrast, our findings suggest that AVPRla also plays a role in female attitudes and behaviour regarding sexual relationships, and this is supported by the findings that AVPR1a is linked to age at first sexual intercourse in both sexes (Prichard et al. 2007). We did not find any mediated effects for $O X T R$, perhaps suggesting that this gene 
influences sexual behaviour along different causal pathways that do not involve personality, attachment styles or cognitive empathy. It is plausible that the interplay between specific gene variants and personality traits identified here, and the different patterns observed between the sexes, underlie recent suggestions of different mating strategies within both sexes as well as between them (Wlodarski and Dunbar 2015).

In comparison with Sociosexual Orientation, the factors influencing Support Network size appears to differ between the sexes. Moreover, whereas the best-fit model of SOI explained $\sim 19-22 \%$ of the variance in each sex, the corresponding models explained only $\sim 11-12 \%$ of Support Network size variance, suggesting that factors other than the dispositional traits measured here play an important role in explaining the latter. Identifying these further factors is a potentially productive line of future research and may involve differing cognitive capacities for processing social information, which will become increasingly complex as social networks expand.

Although individuals who reported being highly avoidant in close friendships tended to have smaller support networks in both sexes, only men's networks were negatively impacted by Neuroticism. Highly neurotic men (that is, who self-reported low emotional stability) had fewer people to turn to for help. Although OXTR, DRD1, and OPRM1 SNPs were found to be associated with Neuroticism, which in turn correlated with Network Size, these trends towards mediated effects failed to reach significance (see ESM). These trends for OXTR broadly support Creswell et al.'s (2015) finding that Neuroticism mediates the relationship between $O X T R$ variation and social network size and diversity. However, we failed to replicate this result specifically for rs1042778. Since Avoidant Attachment showed no genetic associations with the available SNPs, we could not test for mediated effects for this variable (Pearce et al. 2017).

For women, on the other hand, Neuroticism did not seem to play a key role in Support Network Size, but women who were highly anxious in their attachment styles specifically were more likely to have larger support networks. Neuroticism and Anxious Attachment are broadly related: in the present sample, they are significantly positively related in both men and women: $p<0.0001, R^{2}=0.245$ and 0.132 respectively (Table S3; see also Gillath et al. 2008). However, these two variables seem to have opposite effects on Support Network size in the two sexes.

The size of women's support networks was also found to be larger for individuals who were more Agreeable, better able to read emotional expressions in others' faces, and more Extraverted (although RMET and Extraversion scores failed to show significant partial relationships). The endorphin OPRM1 SNP rs495491 was found to indirectly influence women's Network Size via its effect on their degree of Extraversion, so variation in the OPRM1 gene may thus underlie, at least partially, previous findings that Extraverts have larger social networks than Introverts (Pollet et al. 2011). The association between OPRM1 and Extraversion echoes previous work demonstrating that OPRM1 variation, albeit in relation to a different SNP (rs1799971), is linked to individual differences in social hedonia, which relates to how much pleasure an individual experiences in social interactions (Troisi et al. 2010). An individual who experiences more reward through social engagement is likely to be motivated to maintain more relationships, resulting in a larger support network.

There are, inevitably, a number of limitations to this study. Firstly, notwithstanding the large sample size in this study (>750 individuals), the issue of multiple testing means that SNP-specific results presented here should be interpreted with some caution until they have 
been confirmed by more samples. However, discussions over many years within the genetics community also caution us against being too hasty about throwing out the baby with the bathwater. Given that it is likely that complex phenotypes such as those underlying human social cognition and behaviour will involve multiple genes, all contributing small effects, the risk of false negatives is as problematic as the risk of false positives and a balance between these always needs to be struck (Rice et al. 2008). Statistical naivety can often create more problems than it solves. Where suitable largescale databases are available, it may be possible to exploit larger sample sizes that are less prone to type 2 errors. However, few, if any, such databases provide data on the specific social measures of interest here. The main lesson is, perhaps, that those putting such databases together need to have a wider understanding of sociality beyond the simple dyad level (Pearce et al. 2017; Dunbar 2018). That said, some of the concerns in this case are mitigated by the fact that an independent sample, despite being much smaller, yielded broadly similar results to those in Fig. 1 (Pearce et al. 2018a, b). A second issue is the fact that we relied on self-report measures of personality and sociality, and these are always at risk of a subjectivity bias. Future work could incorporate more objective measures such as how many other people in a social network list the participant as a support group member or close friend (e.g. Kwak et al. 2018). However, such a method is logistically much more onerous and certainly outside the scope of studies with the present egocentric design.

Despite these caveats, overall these findings indicate that individual differences in SOI and Support Network Size are partly driven by genetic effects on personality traits, and that these pathways differ between the sexes. Although associations between these genes and human sexual behaviour have been reported previously, we add to our understanding of the complex interplay between variables influencing human sociosexual behaviour by demonstrating that, in part, these genes exert their influence indirectly via Impulsivity in men and Openness in women. Variation in OPRM1 also influences Extraversion, which is positively associated with the size of women's Support Networks. Together, these findings add an important dimension to our understanding of the genetic and dispositional factors underlying how individuals relate to social relationships both with sexual partners and their wider social networks. The fact that there are individual differences in how these are organised both between and within the two sexes raises interesting questions about the selection processes involved. In this respect, these results parallel those reported by Wlodarski et al. (2015; see also Wlodarski and Dunbar 2015) for psychological and anatomical indices of mating strategies. Whether they are held in dynamic equilibrium by frequency-dependent selection or are under active directional selection remains an interesting question yet to be determined.

Acknowledgments The authors would like to thank Dianne Newbury for advice on the genetic analyses and Cole Robertson, Jacques Launay, Bronwyn Tarr, Pádraig MacCarron, Jackie Thompson, and Anna Szala for help with data collection. We would also like to convey thanks to the Edinburgh, Cheltenham and British Science (Bradford) Festivals, and the University of Oxford Natural History Museum, for making the data collection possible. Ethics approval for the study was granted by The University of Oxford Central Ethics Committee (Ref: MS-IDREC-C2-2015-005). The work was funded an ERC Advanced Investigator grant (295663) awarded to RD; writing up was supported by the EU Horizon 2020 FET-Open IBSEN grant (662725). The data are provided as electronic supplementary material.

\section{Compliance with Ethical Standards}

Conflict of interest The authors declare no conflicts of interest. 
Open Access This article is distributed under the terms of the Creative Commons Attribution 4.0 International License (http://creativecommons.org/licenses/by/4.0/), which permits unrestricted use, distribution, and reproduction in any medium, provided you give appropriate credit to the original author(s) and the source, provide a link to the Creative Commons license, and indicate if changes were made.

\section{References}

Aichert, D. S., Wöstmann, N. M., Costa, A., Macare, C., Wenig, J. R., Möller, H.-J., et al. (2012). Associations between trait impulsivity and prepotent response inhibition. Journal of Clinical and Experimental Neuropsychology, 34(10), 1016-1032. https://doi.org/10.1080/13803395.2012.706261.

Aldrich-Blake, F. P. G., Bunn, T., Dunbar, R. I. M., \& Headley, M. (1971). Observations on baboons, Papio anubis, in an arid region in Ethiopia. Folia Primatologica, 15, 1-35.

Archer, J. (2019). The reality and evolutionary significance of human psychological sex differences. Biological Reviews (in press).

Asendorpf, J. B., \& Wilpers, S. (1998). Personality effects on social relationships. Journal of Personality and Social Psychology, 74(6), 1531-1544.

Baron-Cohen, S., Wheelwright, S., Hill, J., Raste, Y., \& Plumb, I. (2001). The "Reading the Mind in the Eyes" Test revised version: A study with normal adults, and adults with Asperger syndrome or high-functioning autism. Journal of Child Psychology and Psychiatry, 42, 241-251.

Bell, E. C., Willson, M. C., Wilman, A. H., Dave, S., \& Silverstone, P. H. (2006). Males and females differ in brain activation during cognitive tasks. Neuroimage, 30, 529-538.

Bhattacharya, K., Gosh, A., Monsivais, D., Dunbar, R. I. M., \& Kaski, K. (2016). Sex differences in social focus across the life cycle in humans. Royal Society Open Science, 3, 160097.

Benenson, J. F., Markovits, H., Fitzgerald, C., Geoffroy, D., Flemming, J., Kahlenberg, S. M., \& Wrangham, R. W. (2009). Males' greater tolerance of same-sex peers. Psychological Science, 20, 184-190.

Benenson, J. F., Markovits, H., Thompson, M. E., \& Wrangham, R. W. (2011). Under threat of social exclusion, females exclude more than males. Psychological Science, 22, 538-544.

Brennan, K. A., Clark, C. L., \& Shaver, P. R. (1998). Self-report measurement of adult attachment: An integrative overview. Attachment Theory and Close Relationships, (April), 46-76.

Burton-Chellew, M., \& Dunbar, R. I. M. (2015). Hamilton's rule predicts anticipated social support in humans. Behavioral Ecology, 26, 130-137.

Carlson, S. M., Moses, L. J., \& Breton, C. (2002). How specific is the relation between executive function and theory of mind? Contributions of inhibitory control and working memory. Infant and Child Development, 14(1), 85-94. https://doi.org/10.1002/icd.

Carlson, S. M., Moses, L. J., \& Claxton, L. J. (2004). Individual differences in executive functioning and theory of mind: An investigation of inhibitory control and planning ability. Journal of Experimental Child Psychology, 87(4), 299-319. https://doi.org/10.1016/j.jecp.2004.01.002.

Carver, C. S., Johnson, S. L., \& Kim, Y. (2015). Mu opioid receptor polymorphism, early social adversity, and social traits. Social Neuroscience, 0919, 1-10. https://doi.org/10.1080/17470919.2015.1114965.

Casey, B. J., Somerville, L. H., Gotlib, I. H., Ayduk, O., Franklin, N. T., Askren, M. K., et al. (2011). Behavioral and neural correlates of delay of gratification 40 years later. Proceedings of the National Academy of Sciences, 108(36), 14998-15003. https://doi.org/10.1073/pnas.1108561108.

Chang, S. C., Glymour, M. M., Rewak, M., Cornelis, M., Walter, S., Koenen, K.C., et al. (2014). Are genetic variations in OXTR, AVPR1A, and CD38 genes important to social integration? Results from two large U.S. cohorts. Psychoneuroendocrinology, 39, 257-268.

Chen, F. S., \& Johnson, S. C. (2012). An Oxytocin Receptor Gene Variant Predicts Attachment Anxiety in Females and Autism-Spectrum Traits in Males. Social Psychological and Personality Science, 3(1), 9399. Retrieved from http://spp.sagepub.com/content/3/1/93.abstractN2 - A molecular genetic approach was used to investigate the relationship between common variants of the oxytocin receptor (OXTR) gene and self-reported social functioning in healthy adults. Females with at 1.

Coates, J. (2015). Women, Men and Language: A Sociolinguistic Account of Gender Differences in Language. London: Routledge.

Costa, B., Pini, S., Gabelloni, P., Abelli, M., Lari, L., Cardini, A., et al. (2009). Oxytocin receptor polymorphisms and adult attachment style in patients with depression. Psychoneuroendocrinology, 34(10), 15061514. https://doi.org/10.1016/j.psyneuen.2009.05.006. 
Creswell, K. G., Wright, A. G. C., Troxel, W. M., Ferrell, R. E., Flory, J. D., \& Manuck, S. B. (2015). OXTR polymorphism predicts social relationships through its effects on social temperament. Social Cognitive and Affective Neuroscience, 10(6), 869-876. https://doi.org/10.1093/scan/nsu132.

Cross, C. P., Cyrenne, D. L. M., \& Brown, G. R. (2013). Sex differences in sensation-seeking: a meta-analysis. Scientific Reports, 3, 2486.

Dàvid-Barrett, T., Rotkirch, A., Carney, J., Behncke Izquierdo, I., Krems, J., Townley, D., McDaniell, E., Byrne-Smith, A., \& Dunbar, R. I. M. (2015). Women favour dyadic relationships, but men prefer clubs. PLoS-One, 10, e0118329.

Del Giudice, M. (2011). Sex differences in romantic attachment: a meta-analysis. Personality and Social Psychology Bulletin, 37(2), 193-214.

de Moor Costa, P. T., Terracciano, A., Krueger, R. F., de Geus, E. J. C., Toshiko, T., et al. (2012). Metaanalysis of genome-wide association studies for personality. Molecular Psychiatry, 17(3), 337-349. https://doi.org/10.1038/mp.2010.128.Meta-analysis.

Denes, A. (2015). Genetic and Individual Influences on Predictors of Disclosure: Exploring Variation in the Oxytocin Receptor Gene and Attachment Security. Communication Monographs, 82(1), 113-133. https://doi.org/10.1080/03637751.2014.993544.

Dunbar, R. I. M. (2010). The social role of touch in humans and primates: behavioural function and neurobiological mechanisms. Neuroscience \& Biobehavioral Reviews, 34, 260-268.

Dunbar, R. I. M. (2012). Bridging the bonding gap: the transition from primates to humans. Philosophical Transactions of the Royal Society of London, 367B, 1837-1846.

Dunbar, R. I. M. (2016). Sexual segregation in human conversations. Behaviour, 153, 1-14.

Dunbar, R. I. M. (2018). The anatomy of friendship. Trends in Cognitive Sciences, 22, 32-51.

Dunbar, R. I. M., \& Machin, A. (2014). Sex differences in relationship conflict and reconciliation. Journal of Evolutionary Psychology, 12, 109-133.

Dunbar, R. I. M., \& Shultz, S. (2017). Why are there so many explanations for primate brain evolution? Philosophical Transactions of the Royal Society, B: Biological Sciences, 372(1727), 20160244. https://doi.org/10.1098/rstb.2016.0244.

Dunbar, R. I. M., \& Spoors, M. (1995). Social networks, support cliques, and kinship. Human Nature, 6(3), 273-290. https://doi.org/10.1007/bf02734142.

Dyble, M., van Leeuwen, A., \& Dunbar, R. I. M. (2015). Gender differences in Christmas gift-giving. Evolutionary Behavioral Sciences, 9, 140-144.

Eisenberg, D. T. A., Campbell, B., MacKillop, J., Lum, J. K., \& Wilson, D. S. (2007). Season of birth and dopamine receptor gene associations with impulsivity, sensation seeking and reproductive behaviors. PLoS One, 2(11). https://doi.org/10.1371/journal.pone.0001216.

Feldman Barrett, L., Lane, R. D., Sechrest, L., \& Schwartz, G. E. (2000). Sex differences in emotional awareness. Personality and Social Psychology Bulletin, 26, 1027-1035.

Gardner, W. L., \& Gabriel, S. (2004). Gender differences in relational and collective interdependence: implications for self-views, social behavior, and subjective well-being. In A. H. Eagly, A. E. Beall, \& R. J. Sternberg (Eds.), The Psychology of Gender (pp. 169-191). New York: Guilford Press.

Ghosh, A., Monsivais, D., Bhattacharya, K., Dunbar, R. I. M., \& Kaski, K. (2019). Quantifying gender preferences in human social interactions using a large cellphone dataset. EPJ Data Science, 8, 9.

Gillath, O., Shaver, P. R., Baek, J.-M., \& Chun, D. S. (2008). Genetic Correlates of Adult Attachment Style. Personality and Social Psychology Bulletin, 34(10), 1396-1405. https://doi.org/10.1177 /0146167208321484.

Gosling, S. D., Rentfrow, P. J., \& Swann Jr., W. B. (2003). A very brief measure of the Big-Five personality domains. Journal of Research in Personality, 37(6), 504-528. https://doi.org/10.1016/S0092-6566(03 )00046-1.

Garamszegi, L. Z. (2006). Comparing effect sizes across variables: generalization without the need for Bonferroni correction. Behavioral Ecology, 17(4), 682-687.

Hall, J. A. (2019). How many hours does it take to make a friend? Journal of Social and Personal Relationships, 36, 1278-1296.

Hall, J. A., \& Matsumoto, D. (2004). Gender differences in judgments of multiple emotions from facial expressions. Emotion, 4, 201-206.

Hamidovic, A., Dlugos, A., Skol, A., Palmer, A. A., \& de Wit, H. (2009). Evaluation of genetic variability in the dopamine receptor D2 in relation to behavioral inhibition and impulsivity/sensation seeking: An exploratory study with d-amphetamine in healthy participants. Experimental and Clinical Psychopharmacology, 17(6), 374-383. https://doi.org/10.1037/a0017840.

Hayes, A. F. (2013). Introduction to Mediation, Moderation, and Conditional Process Analysis: A RegressionBased Approach. New York: The Guilford Press. 
Hill, R. A., \& Dunbar, R. I. M. (2003). Social network size in humans. Human Nature, 14, 53-72.

Jang, K. L., Livesley, W. J., \& Vemon, P. A. (1996). Heritability of the Big Five Personality Dimensions and Their Facets: A Twin Study. Journal of Personality, 64(3), 577-592. https://doi.org/10.1111/j.14676494.1996.tb00522.x.

Kam, J. W. Y., Dominelli, R., \& Carlson, S. R. (2012). Differential relationships between sub-traits of BIS-11 impulsivity and executive processes: An ERP study. International Journal of Psychophysiology, 85(2), 174-187. https://doi.org/10.1016/j.ijpsycho.2012.05.006.

Kiesow, H., Dunbar, R. I. M., Kable, J. W., Kalenscher, T., Vogeley, K., et al. (2019). 10,000 social brains: sex differentiation in human brain anatomy. Scientific Advances (in press).

Kim, H.-N., Roh, S.-J., Sung, Y. A., Chung, H. W., Lee, J.-Y., Cho, J., et al. (2013). Genome-wide association study of the five-factor model of personality in young Korean women. Journal of Human Genetics, 58(10), 667-674. https://doi.org/10.1038/jhg.2013.75.

Kokko, H., \& Johnstone, R. A. (2001). The evolution of cooperative breeding through group augmentation. Proceedings of the Royal Society of London, 268B(1463), 187-196.

Kwak, S., Joo, W. T., Youm, Y., \& Chey, J. (2018). Social brain volume is associated with in-degree social network size among older adults. Proceedings of the Royal Society of London, 285B, 20172708.

Launay, J., Pearce, E., Wlodarski, R., van Duijn, M., Carney, J., \& Dunbar, R. I. M. (2015). Higher-order mentalising and executive functioning. Personality and Individual Differences, 86(0), 6-14. https://doi. org/10.1016/j.paid.2015.05.021.

Lee Raby, K., Cicchetti, D., Carlson, E. A., Egeland, B., \& Andrew Collins, W. (2013). Genetic contributions to continuity and change in attachment security: A prospective, longitudinal investigation from infancy to young adulthood. Journal of Child Psychology and Psychiatry, and Allied Disciplines, 54(11), 12231230. https://doi.org/10.1111/jcpp.12093.

Lo, M., Hinds, D. A., Tung, J. Y., Franz, C., Fan, C., Wang, Y., et al. (2017). Genome-wide analyses for personality traits identify six genomic loci and show correlations with psychiatric disorders., 49(1), 1-8. https://doi.org/10.1038/ng.3736.

Logan, G. D., Schachar, R. J., \& Tannock, R. (1997). Impulsivity and inhibitory control. Psychological Science, 8(1), 60-64.

Loseth, G. E., Ellingsen, D. M., \& Leknes, S. (2014). State-dependent $\mu$-opioid modulation of social motivation - a model. Frontiers in Behavioral Neuroscience, 8, 430.

Lucht, M. J., Barnow, S., Sonnenfeld, C., Ulrich, I., Grabe, H. J., Schroeder, W., et al. (2013). Associations between the oxytocin receptor gene (OXTR) and "mind-reading" in humans-An exploratory study. Nordic Journal of Psychiatry, 67(1), 15-21. https://doi.org/10.3109/08039488.2012.700731.

Lukaszewski, A. W., \& Roney, J. R. (2011). The origins of extraversion: joint effects of facultative calibration and genetic polymorphism. Personality and Social Psychology Bulletin, 37, 409-421. https://doi. org/10.1177/0146167210397209.

Machin, A., \& Dunbar, R. I. M. (2011). The brain opioid theory of social attachment: a review of the evidence. Behaviour, 148, 985-1025.

Machin, A., \& Dunbar, R. I. M. (2013). Sex and gender in romantic partnerships and best friendships. Journal of Relationship Research, 4, e8.

MacLean, E. L., Hare, B., Nunn, C. L., Addessi, E., Amici, F., Anderson, R. C., et al. (2014). The evolution of self-control. Proceedings of the National Academy of Sciences, USA, 111(20), E2140-E21E8.

McCrae, R. R., \& Costa, P. T. (1992). Personality Trait Structure as a Human Universal, 52(5), 509-516.

Mehta, C. M., \& Strough, J. (2009). Sex segregation in friendships and normative contexts across the life span. Developmental Review, 29, 201-220.

Miller, W. B., Past, D. J., MacMurray, J., Chiu, C., Wu, H., \& Comings, D. (1999). Dopamine Receptor Genes Are Associated With Age At First Sexual Intercourse. Journal of Biosocial Science, 31(1), S0021932099000437. https://doi.org/10.1017/S0021932099000437.

Miritello, G., Moro, E., Lara, R., Martinez-Lopez, R., Belchamber, J., Roberts, S. G. B., \& Dunbar, R. I. M. (2013). Time as a limited resource: Communication Strategy in Mobile Phone Networks. Social Networks, 35(1), 89-95.

Mischel, W., \& Yuichi Shoda, M. L. R. (1976). Delay of gratification in children. Science, 244(4907), 933-938.

Moffitt, T., Caspi, A., Rutter, M., \& Silva, P. (2001). Sex Differences in Antisocial Behaviour: Conduct Disorder, Delinquency, and Violence in the Dunedin Longitudinal Study. Cambridge: Cambridge University Press.

Nakagawa, S. (2004). A farewell to Bonferroni: the problems of low statistical power and publication bias. Behavioral Ecology, 15(6), 1044-1045.

Narum, S. R. (2006). Beyond Bonferroni: less conservative analyses for conservation genetics. Conservation İenetics, 7(5), 783-787. 
Pearce, E., Wlodarski, R., Machin, A., \& Dunbar, R. I. M. (2017). Variation in the $\beta$-endorphin, oxytocin, and dopamine receptor genes is associated with different dimensions of human sociality. Proceedings of the National Academy of Sciences, 114(20), 5300-5305.

Pearce, E., Wlodarski, R., Machin, A., \& Dunbar, R. I. M. (2018a). Associations between neurochemical receptor genes, 2D:4D, impulsivity and relationship quality. Biology Letters, 14(20180642). https://doi. org/10.1098/rsbl.2018.0642.

Pearce, E., Wlodarski, R., Machin, A., \& Dunbar, R. I. M. (2018b). The influence of genetic variation on social disposition, romantic relationships and social networks: a replication study. Adaptive Human Behavior and Physiology.

Pearce, E., Wlodarski, R., Machin, A., \& Dunbar, R. I. M. (2019). Exploring the links between dispositions, romantic relationships, support networks and community inclusion in men and women. PLoS One, 14, e0216210.

Penke, L., \& Asendorpf, J. B. (2008). Beyond global sociosexual orientations: A more differentiated look at sociosexuality and its effects on courtship and romantic relationships. Journal of Personality and Social Psychology, 95(5), 1113-1135. https://doi.org/10.1037/0022-3514.95.5.1113.

Pollet, T. V., Roberts, S. G. B., \& Dunbar, R. I. M. (2011). Extraverts Have Larger Social Network Layers. Journal of Individual Differences, 32(3), 161-169. https://doi.org/10.1027/1614-0001/a000048.

Powell, J., Lewis, P. A., Roberts, N., Garcia-Finana, M., \& Dunbar, R. I. M. (2012). Orbital prefrontal cortex volume predicts social network size: an imaging study of individual differences in humans. Proceedings of the Royal Society B: Biological Sciences, 279(1736), 2157-2162. https://doi.org/10.1098 /rspb.2011.2574.

Power, R. A., \& Pluess, M. (2015). Heritability estimates of the Big Five personality traits based on common genetic variants. Translational Psychiatry, 5(7), e604-e604. https://doi.org/10.1038/tp.2015.96.

Prichard, Z. M., Mackinnon, A. J., Jorm, A. F., \& Easteal, S. (2007). AVPR1A and OXTR polymorphisms are associated with sexual and reproductive behavioral phenotypes in humans. Human Mutation, 28(11), 1150. https://doi.org/10.1002/humu.9510.

Proverbio, A. M., Zani, A., \& Adorni, R. (2008). Neural markers of a greater female responsiveness to social stimuli. BMC Neuroscience, 9, 56.

Purcell, S., Neale, B., Todd-Brown, K., Thomas, L., Ferreira, M. A. R., Bender, D., et al. (2007). PLINK: A tool set for whole-genome association and population-based linkage analyses. American Journal of Human Genetics, 81, 559-575.

Reniers, R., Corcoran, R., Drake, R., Shryane, N., \& Völlm, B. (2009). P02-150 The QCAE: A questionnaire of cognitive and affective empathy. European Psychiatry, 24, S840. https://doi.org/10.1016/S0924-9338 (09)71073-9.

Rhoades, B. L., Greenberg, M. T., \& Domitrovich, C. E. (2009). The contribution of inhibitory control to preschoolers' social-emotional competence. Journal of Applied Developmental Psychology, 30(3), 310320. https://doi.org/10.1016/j.appdev.2008.12.012.

Rice, T. K., Schork, N. J., \& Rao, D. C. (2008). Methods for Handling Multiple Testing. In B. T.-A. in Genetics (Ed.), Genetic Dissection of Complex Traits (Vol. Volume 60, pp. 293-308). Academic Press. 10.1016/S0065-2660(07)00412-9.

Roberts, S. G. B., \& Dunbar, R. I. M. (2011). The costs of family and friends: An 18-month longitudinal study of relationship maintenance and decay. Evolution and Human Behavior, 32(3), 186-197. https://doi. org/10.1016/j.evolhumbehav.2010.08.005.

Roberts, S. B. G., \& Dunbar, R. I. M. (2015). Managing relationship decay: network, gender, and contextual effects. Human Nature, 26, 426-450.

Rodrigues, S. M., Saslow, L. R., Garcia, N., John, O. P., \& Keltner, D. (2009). Oxytocin receptor genetic variation relates to empathy and stress reactivity in humans. Proceedings of the National Academy of Sciences, 106(50), 21437-21441. Retrieved from http:/www.pnas.org/content/106/50/21437.abstract

Rothman, K. J. (1990). No adjustments are needed for multiple comparisons. Epidemiology, 1(1), 43-46.

Saramäki, J., Leicht, E., López, E., Roberts, S. 1. G., Reed-Tsochas, F., \& Dunbar, R. I. M. (2014). The persistence of social signatures in human communication. Proceedings of the National Academy of Sciences, USA, 111, 942-947.

Schmitt, D. P., \& Buss, D. M. (2000). Sexual Dimensions of Person Description: Beyond or Subsumed by the Big Five? David P. Schmitt, 177, 141-177. https://doi.org/10.1006/jrpe.1999.2267.

Schmitt, D. P., \& Shackelford, T. K. (2008). Big Five Traits Related to Short-Term Mating: From Personality to Promiscuity across 46 Nations, 6(2), 246-282.

Schneiderman, I., Kanat-Maymon, Y., Ebstein, R. P., \& Feldman, R. (2014). Cumulative risk on the oxytocin receptor gene (OXTR) underpins empathic communication difficulties at the first stages of romantic love. Social Cognitive and Affective Neuroscience, 9(10), 1524-1529. https://oi.org/10.1093/scan/nst142. 
Schulz, K. F., \& Grimes, D. A. (2005). Multiplicity in randomised trials I: endpoints and treatments. Lancet, 365(9470), 1591-1595.

Shackelford, T. K., \& Goetz, A. T. (2008). Personality, Marital Satisfaction, and Probability of Marital Infidelity, 6(1), 13-25.

Shultz, S., \& Dunbar, R. I. M. (2010). Species differences in executive function correlate with hippocampus volume and neocortex ratio across non-human primates. Journal of Comparative Psychology, 124, 252-260.

Spinella, M. (2007). Normative data and a short form of the Barratt Impulsiveness Scale. International Journal of Neuroscience, 117(3), 359-368. https://doi.org/10.1080/00207450600588881.

Stiller, J., \& Dunbar, R. I. M. (2007). Perspective-taking and memory capacity predict social network size. Social Networks, 29(1), 93-104. https://doi.org/10.1016/j.socnet.2006.04.001.

Streiner, D. L., \& Norman, G. R. (2011). Correction for multiple testing: is there a resolution? CHEST, 140(1), 16-18.

Sutcliffe, A. G., Dunbar, R. I. M., Binder, J., \& Arrow, H. (2012). Relationships and the social brain: Integrating psychological and evolutionary perspectives. British Journal of Psychology, 103, 149-168. https://doi.org/10.1111/j.2044-8295.2011.02061.x.

Troisi, A., Frazzetto, G., Carola, V., Di Lorenzo, G., Coviello, M., D’Amato, F. R., et al. (2010). Social hedonic capacity is associated with the $\mathrm{A} 118 \mathrm{G}$ polymorphism of the mu-opioid receptor gene (OPRM1) in adult healthy volunteers and psychiatric patients. Social Neuroscience, 6(1), 88-97. https://doi. org/10.1080/17470919.2010.482786.

Varga, G., Szekely, A., Antal, P., Sarkozy, P., Nemoda, Z., Demetrovics, Z., \& Sasvari-Szekely, M. (2012). Additive effects of serotonergic and dopaminergic polymorphisms on trait impulsivity. American Journal of Medical Genetics, Part B: Neuropsychiatric Genetics, 159 B(3), 281-288. https://doi.org/10.1002 /ajmg.b.32025.

Vigil, J. M. (2007). Asymmetries in the friendship preferences and social styles of men and women. Human Nature, 18, 143-161.

Vukasović, T., \& Bratko, D. (2015). Heritability of personality: A meta-analysis of behavior genetic studies. Psychological Bulletin, 141(4), 769-785. https://doi.org/10.1037/bul000001.

Walum, H., Lichtenstein, P., Neiderhiser, J. M., Reiss, D., Ganiban, J. M., Spotts, E. L., et al. (2012). Variation in the Oxytocin Receptor Gene Is Associated with Pair-Bonding and Social Behavior. Biological Psychiatry, 71(5), 419-426. https://doi.org/10.1016/j.biopsych.2011.09.002.

Walum, H., Westberg, L., Henningsson, S., Neiderhiser, J. M., Reiss, D., Igl, W., et al. (2008). Genetic variation in the vasopressin receptor 1a gene (AVPR1A) associates with pair-bonding behavior in humans. Proceedings of the National Academy of Sciences, 105(37), 14153-14156.

Way, B. M., Taylor, S. E., \& Eisenberger, N. I. (2009). Variation in the $\mu$-opioid receptor gene (OPRM1) is associated with dispositional and neural sensitivity to social rejection. Proceedings of the National Academy of Sciences, 106(35), 15079-15084. Retrieved from http://www.pnas.org/content/106/35 /15079.abstractN2 - Scientific understanding of social pain - the hurt feelings resulting from social rejection, separation, or loss - has been facilitated by the hypothesis that such feelings arise, in part, from some of the.

Wei, M., Russell, D. W., Mallinckrodt, B., \& Vogel, D. L. (2007). The Experiences in Close Relationship Scale (ECR)-Short Form: Reliability, Validity, and Factor Structure. Journal of Personality Assessment, 88(2), 187-204. https://doi.org/10.1080/00223890701268041.

Wilson, M. C., Zilioli, S., Ponzi, D., Henry, A., Kubicki, K., Nickels, N., \& Maestripieri, D. (2015). Cortisol reactivity to psychosocial stress mediates the relationship between extraversion and unrestricted sociosexuality. Personality and Individual Differences, 86, 427-431.

Wlodarski, R., \& Dunbar, R. I. M. (2015). Within-sex mating strategy phenotypes: evolutionary stable strategies? Human Ethology Bulletin, 30, 99-108.

Wlodarski, R., Manning, J., \& Dunbar, R. I. M. (2015). Stay or stray? Evidence for alternative mating strategy phenotypes in both men and women. Biology Letters, 11(2), 20140977. https://doi.org/10.1098 /rsbl.2014.0977.

Wu, K., Chen, C., Moyzis, R. K., Greenberger, E., \& Yu, Z. (2016). Gender Interacts with Opioid Receptor Polymorphism A118G and Serotonin Receptor Polymorphism -1438 A/G on Speed-Dating Success. Human Nature, 244-260. https://doi.org/10.1007/s12110-016-9257-8.

Yamagata, S., Suzuki, A., Spinath, F. M., Livesley, W. J., \& Jang, K. L. (2006). Is the Genetic Structure of Human Personality Universal ? A Cross-Cultural Twin Study From North America, Europe, and Asia, 90(6), 987-998. https://doi.org/10.1037/0022-3514.90.6.987.

Publisher's Note Springer Nature remains neutral with regard to jurisdictional claims in published maps and institutional affiliations. 


\section{Affiliations}

\section{Eiluned Pearce $^{1} \cdot$ Rafael Wlodarski $^{1} \cdot$ Anna Machin $^{1} \cdot$ Robin I. M. Dunbar ${ }^{1}$}

Robin I. M. Dunbar

robin.dunbar@psy.ox.ac.uk

1 Social \& Evolutionary Neuroscience Research Group, Department of Experimental Psychology, University of Oxford, Anna Watts Building, Radcliffe Observatory Quarter, Woodstock Rd, Oxford OX2 $6 \mathrm{GG}, \mathrm{UK}$ 